\title{
Cost-effectiveness of recruitment methods in a population- based epidemiological study: the Melbourne Visual Impairment Project
}

\author{
Patricia M. Livingston and Charles S. Guest \\ Department of Ophthalmology, University of Melbourne
}

Angela Bateman and Norman Woodcock
Riny Morgan Research Centre, Melbourne

Hugh R. Taylor

Department of Ophthalmology, University of Melbourne

\begin{abstract}
Abetract: The cost-effectiveness of five recruitment methods was evaluated in determine the best method of encouraging eligible persons to participate in the Melbourne Visual Impairment Project (a populationbased epidemiological study). The evaluation was divided into two phases. Phase 1 included one of (wo) types of initial contact. by direct personal contact or by telephone. Phase 2 involved recruiting residents after an altempt had been made by either the telephone or the dowrstep approach, and included a second altempt by a field interviewer, subsequent attempts by senior field staff, and finally. financial incentives. The cost-effectiveness of each methexd was determined by dividing the approarti's crost by ihe effectiveness ratio. We identified 269 eligible households with $\$ 56$ eligible residents. An 89 per cent response rale was achieved at the examination centre, comprising 61 per cent from Phase 1 and 28 per cent from Phase 2. Alitough both recruitment methods in Phase I were equally cost-elfective, there was a signilicant difference in the effectiveness of each methest in actually rec ruiting residents. The densrstep methext was more costly per attender but was far more effective at 76 per cent recruitment than the telephone neethoxt at 47 per cent $(P<0.001$ ). We have demonstrated a practical iwo-stage approach (the donrstep methoxd in Phase 1 and follow-up strategies in Phase 2) to population-based recruitment involving the middle 10 elderly age group that should be relevant to many epidemiological studies. (Aust J Public Health 1994; 18: 314-18)
\end{abstract}

F Tormal evaluation of recruitment strategies is limited, clespite recruitment having significant implications for the planning and success of pxpulation-based screening programs. Recruitment strategies are designed (1) enc(surage eligible persons

Correspondence III Ms P.M. I.ivingston. F.pidemiolesyy Rescarch ('nit. Depurtuxent of (Mphthalnkteny. IIniversity of Melboume. RVF.K.H. 32 (jishome Sirert. last Melbuume. Vic 9002. Fax (03) liti2 3 H.59.
(1) participate in peppulation-based epidemiological scuclies. Such scuclies have public healih relevance in the investigation of disease prevalence and assoxiated risk factors, the planning of health services and community education.

A problem in studies of vision in the middle (1) elderly age group is that of obtaining adequate participation to ensure that the sample is representative.' low participation rates may undermine the results of the population sample screened. Participants may 
dilfer from those who do not participate on importalli variables such as age. soxiofeconomic status, vision loss, and general health factors.' Householders who refuse (1) disclose any information may (omlain a higher proportion of residents who are suffering from visual impairnent and may not be aware of their impairment, have pexor vision that has already been fully assessed, and more generally are socially disadvantaged, have prover health, and higher mortality. i"

The Melbourne Visual Impairnent Project is a population-based epidemiolongical study designed in increase our understanding of the prevalence and severity of major ocular disorders, for example, catarace, glaucoma and retinal diseases, in those 40 years of age and over. This will be achieved by offering a comprehensive eye examination at no charge to eligible residents at a local examination centre in each of ilie nine sample areas randomly selected as representative of the Mellonurne statistical division.

The aims of the pilost study were in evaluate several methexds of approaching persons to encourage parlicipation at a lixal screening centre and io assess the feasibility and acceptability of the survey instruments and resting procedures.

\section{Method}

A pilot study was conducted in two adjacent census collector districts in the Albert Park area, a Melbourne metropolitan suburb. Albert Park was one of nine randomly selected areas. The exanination centre was situated in a church hall within the sample area and screening was conducted from May through (1) August 1992.

Recruitment was divided into (wo phases and the cost-effectiveness of each was evaluated separately. Phase 1 involved (wo) recruitment methods, either the 'd(x)rstep' (field interviewers contacted households and interviewed eligible residents in person) or telephone (telephone interviewers contacted households and interviewed eligible residents only by telephone). The follow-up (Phase 2) involved three recruitment methods.10 secure the participation of those in the sample who had not taken part in the examination.

A computerised list of addresses in the sample area with corresponding telephone numbers was obtained from a sofiware computer company. Households were randombly selected for either dexurstep interview or telephone recruitment. Households without a telephone were automatically assigned to the $d(x) r$ step approach. Two experienced ielephone and field interviewers from the Roy Morgan Research Centre were allocated a weekly assignment of addresses within each of the two census collector districts, and the household census and interviews were conducted over the following week. A doorstep visit or telephone contact was attempted with all households. Up in ten repeal visits or te-lephone calls were niacle at diflerent limes (weekend, weekday evening, weekday p.m.. weekday a.m.) to complete the assignment; however, most interviews were conducted at the time of the houschold census. In situations where the household or resident was known to be absent from the area for a period of time (less than three nomths). the file was retained by the interviewer until contact was made.
The first step in the recruitnent process was handdelivery of an unpersonalised letter of introduction and language insert (o) each household in the sample area, three to four days before the doxsstep or telephone household census and interview commenced. A household was defined as all people usually living at an address or residence. who may or may not be related. The letter of introduction provided a general explanation of the project, its purposes and the benefits of attending the free eye examination. The language insert (translated into 11 common languages) invited non-E.nglish-speaking residents (o) contact the Telephone Interpreter Service for further details. Translators from the service were briefed about the project.

The goal of the private household census was (1) determine the number, names and ages of all those eligible, that is, all persons 40 years of age or over resident in the sample area for six months or more. The 1991 census definition of a "permanent resident" was used." A short interview was allempted with all eligible residents to elicit demographic data and collect essential information on eye symptoms and use of eye health care services. An invitation to attend a free eye examination at the local examination centre was offered. The interview took approximately ten minutes per eligible person.

All households or eligible residents who did not provide any household information, answer general questions, or attend the eye examination were allocated to the Phase 2 recruitment proxedure, and in the first instance, contacted by doorstep interviewers on up to two separate occasions to recruit them. For example, if the telephone interviewer was unsuccessful in recruiting the eligible resident or household, or the resident could not be contacted by telephone after 10 attempts, the file was handed over ic a doorstep interviewer to attempt recruitment. If a door-. step interviewer was unsuccessful in an initial recruitment attempt, the file was handed over to the second doorstep interviewer. The second attempt was conducted within three weeks of the initial refusal or noncontact. If the second doorstep attempt was unsuccessful, Department of Ophthalinology senior field staff continued with the recruitment process, and altempts to recruit nonparticipants by either approach were made after iwo weeks had lapsed.

If this strategy was unsuccessful, a financial incentive of $\$ 10$ cash (iflucluding a set appointment to attend the examination centre) was offered in a personalised letter forwarded (1) the household or (1) the eligible resident which could be collected following the eye examination. If there was no response, a second letter was sent with another appointment scheduled and an incentive of $\$ 25$ cash was offered.

Home visits, transport and a modified screening service for ineligible relatives or friends were offered at all stages of the recruitment process to encourage eligible residents (1) participate.

A successful recruitment was defined as the attendance at a local examination centre by an eligible resident after an appointment had been secured by a Roy Morgan Research Centre interviewer or a Depant. ment of Ophthalmology senior field staff niember.

To estimate the costs of the various strategies, interviewer costs comprised salary (including 


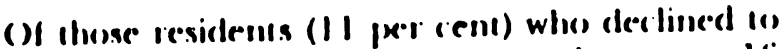

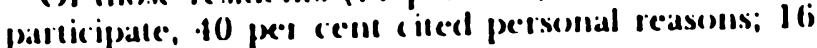
per cenl were noll interested; 5 per cent were appre. hensive; 1 per cent referred lo language dilficulties, and $\$ 4$ per cent specified other reasons, for example. satisfaction with current oxular care, a recent eye examination, they were (o) busy or had a family or a physical illness.

\section{Discussion}

An evaluation of the cost-effectiveness of recruitment strategies is important (1) the rational planning of screening programs. Success in recruiting residents for poppulation-based studies is often a factor in deternining whether or not a study will proceed." When the propessal involves the recruitment of a population sample of thealthy participants." the task of recruiting poses a significant challenge for researchers. Participants are unlikely to be found in the more traditional sources of recruitment, that is, hospital settings or clinic $s$, and it is therefore necessary (1) develop imaginative stralcgies (1) recruit from the general population.

Despite the potential influence recruitment methoxls have on public healih programs, few epidemiological studies have evaluated the effectiveness of their recruitment methods. ${ }^{11.15}$ The difficulties associated with recruitment are magnified in surveys dealing with issues such as eye disease because of the equipment necessary for an adequate ophthalmic examination and the time the examination takes, especially if dilating drops are needed for a fundal examination.

In this study, we demonstrated that the direct persollal ol clocersiep approalch in lhase I was the most

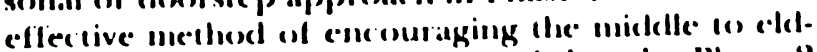
erly age group (o participate, and that the Phase? strategies proved useful supplements $t(1)$ the recruitment proxess.

The success of the docorstep method may be attributed io four factors. Firstly, interviewers had an cpportunity (1) develop a rapport with the resident. not always pessible using the telephone. Secondly, time spent at the door may have helped co convince a reluctant resident io participaste; it is easier for a resident (1) terminate a lelephone (all with an unknown caller. Thirdly, the interviewer, by providing visible identification, had the opportunity (o) allay concerns about validity of the project or interviewer, an important consideration for a person living alone or an elderly resident. And finally, the doorstep interviewers were aged over 40; residents may have more readily identified with and irusted the interviewers and therefore agreed (1) participate in the project.

Both methods of recruitment, nevertheless, have advantages and disadvantages. The disadvantages of the doxistep method are all (o)st related: additional salary costs incurred by the field interviewers and travel expenses. The advantages of direct personal contact and the resultant high response rate have been disiussed above. (One disadvantage of using the lelephone approach is that house-holds without telephones (4 10 5 per cent) or subscribers with silent lines (10 10 12 per ceni) cannos be reached. "it Cinsequently, doxirstep recruitment would always be necessary for at least 10 per cent of the sample pospu- lation. Ancoliner disadvallatage is the limiled rappent lhat is cleveloped by lice le.lephome inlerviewer

The advantages of telephone interviewing anc thal first, it is less costly (o) conduct the questionnaite on the ielephone, because there are not iravel costs and recontact is a malter of a telephone call. If the resident is not home, it is a simple matter (1) dial the next telephone number and attempt II) contact the next household or eligible resident. Second, time spent conversing with the respondent is limited. so more residents can be contacted in a given time.

The success of Phase 2 as an adjuncl lo the initial recruitment prexess (an be altributed il several reasons. Firstly, the location of the examination centre within the sample area provided the upporlunity for residents (I) walk or drive a short distance 10 the centre; it proved io be an impontant consideration for reluctant respendents. The distance of the screening centre was considered an important leasun for the failure of the Visual Acuity Impairment Survey Pilos study, ${ }^{+}$and explained in part the low palt tic ipation rate achieved by the Framingham tiye Siudy.' Secondly, the benefits of a thorough eye examination (regarded as an important feature in the tecruitment process in the visual acuity study') were reemphasised during the second and subsequent atcempts. Thirdly, some who initially declined (o) participate reconsidered a home visit as an attractive alternative to attending the screening centre. Home visits were not offered by (Gibson et al., a possible reason for the study's low response rate, ${ }^{i}$ and a likely deterrent (1) attendance by the frail."

Many other factors reinforced at the second and subsequent attempts contributed to the success of Phase 2: the significance of a free screening service and emphasis on alt ruistic monives; the importance of improving cur understanding of eye disease within the community; the availability of iransport 11 and from the screening centre; the availability of out-ofhours appointment for full-time and shift workers. and modified eye tests for ineligible relatives or friends.

Recruitment by senior field staff was both cheaper and more effective than the doxrstep approach in Phase 2 . This may have been because of the different staff involved, or because of the time between the second and subsequent attempts, enabling reluctant residents in reconsider and hear possitive feedback from neighbours who had attended the screening centre. The identification of senior field staff as university employees allowed the people approached (i) verify the authenticity of the project. Repeated telephone and/or docrstep visits by the senior field staff proved beneficial, with 130 telephone or d(x)rstep attempts nade.

Although financial incentives were not costeffective nor effective, we believed that those who altended the free eye test after receiving an incentive letter were atypical of the population sample, and as discussed in the introduction, their participation will provide valuable information on the types of citizens who would otherwise not have participated in the project. For example, pathology was evident in $\mathbf{5 0}$ per cent of those who attended following a financial incentive.

This approach will continue to be employed in the future. Information collected on the reasons why 
Table 1: Age and sex distribution of residents who participoted af the screening centre

\begin{tabular}{|c|c|c|c|c|c|c|c|c|c|c|c|c|c|}
\hline & \multicolumn{2}{|c|}{40 to 49} & \multicolumn{2}{|c|}{50 10 59} & \multicolumn{2}{|c|}{601069} & \multicolumn{2}{|c|}{70 to 79} & $\cdot$ & \multicolumn{2}{|c|}{80 10 89} & \multicolumn{2}{|c|}{$90+$} \\
\hline $\begin{array}{l}\text { Males } \\
\text { Fomoles }\end{array}$ & $\begin{array}{l}48 \\
54\end{array}$ & $\begin{array}{l}15 \\
17\end{array}$ & $\begin{array}{l}32 \\
41\end{array}$ & $\begin{array}{l}10 \\
13\end{array}$ & $\begin{array}{l}32 \\
43\end{array}$ & $\begin{array}{l}10 \\
14\end{array}$ & $\begin{array}{l}18 \\
27\end{array}$ & $\begin{array}{l}6 \\
8\end{array}$ & & $\begin{array}{r}7 \\
11\end{array}$ & $\begin{array}{l}2 \\
3\end{array}$ & $\begin{array}{l}1 \\
2\end{array}$ & $\begin{array}{c}0.5 \\
1\end{array}$ \\
\hline
\end{tabular}

472 households in the somple oreo
Doorstep
$56(54 \%)$
Tolephone

Household

$$
\text { EL IE NC. }
$$

$139 \quad 1125$

Eligible residents

174

EL $\quad$ IE $\quad N C$

182

Phose 1

First oftempt success 132

Nonporticipants

Phose 2

2nd doorstep oftempt

2nd doorstep success

Nonparticipants

Senior field staff oftempts

Senior field staft success

Nonporticiponts

Incentive $(\$ 10)$

$\$ 10$ success

Nonparticipants

Incentive (\$25)

$\$ 25$ success

Nonparticiponts
84

38

98

51

$63^{\circ}$

6

$42^{\circ}$

4.
Figure I, Success of eoch method of recruitment from 472 heruseholeds

(a) EI - eliguble housohold

(b) IE - ineligible household

(c) NC = no contocl

(d) Includes letters to households which had relused 10 provide any informotion and where ll was known that at least one person was eligible 10 participate

(e) Two residents from two households ollended

oncosts), travel, telephone (including repeat attempts) and administration expenses; printing costs assixiated with both methods were determined; senior field staff costs were estimated by dividing the salary by the hours spent recruiting, which was then divided by the number of attempts in convert a residenit (1) participate. This amounted io $\$ 15$ for each attempt. Financial incentive costs included adminisirative costs and reimbursement (o) participants. The cost per recruitment strategy was calculated by summing the costs incurred divided by the number of successful recruitments for each strategy. The effectiveness ratio was calculated by dividing the number of successful recruitments by the number of eligible residents for each strategy.

Table 2: The cost-effectiveness of two recruitment methods employed in Phase 1

\begin{tabular}{|c|c|c|c|c|c|}
\hline $\begin{array}{l}\text { Recruitment } \\
\text { type }\end{array}$ & $\begin{array}{l}\text { Number } \\
\text { ottempled }\end{array}$ & Cost & $\begin{array}{c}\text { Effocti } \\
n\end{array}$ & $\begin{array}{c}\text { oness } \\
\%\end{array}$ & $\begin{array}{c}\text { Cost. } \\
\text { offectiveness } \\
\mathbf{S}\end{array}$ \\
\hline $\begin{array}{l}\text { Doonstep } \\
\text { Telephone }\end{array}$ & $\begin{array}{l}174 \\
182\end{array}$ & $\begin{array}{l}41 \\
25\end{array}$ & $\begin{array}{r}132 \\
86\end{array}$ & $\begin{array}{l}76^{\circ} \\
47^{\circ}\end{array}$ & $\begin{array}{l}54 \\
53\end{array}$ \\
\hline
\end{tabular}

$r^{2}-31.26, \cdot p<0.001$
The cost-effectiveness of each strategy was determined by dividing the approach's cost by the effectiveness ratio. The lower the cost-effectiveness demonstrated by a particular recruitment method, the greater return for each dollar spent.

Information was also collected on the reasons provided by residents who declined (o) participate.

fihical approval was obtained from the Royal Vic(orian tye and Far Hospital Human Research and fihics (immittee to carry out the recruitment procedures and comprehensive eye examination, prior to commencing the pilot study.

\section{Results}

In total, 472 households were approached in the (wo) census collec(o)r districts, and eligibility stalus was determined in 467 households during the initial doxistep or telephone contact (Figure 1). ()f those approached. 269 eligible households and 356 eligible residents were identified.

A cotal of 174 eligible residents was identified by the doxrstep recruitment method, and 182 by the telephone approach. Overall, 316 residents $(89$ per cent) participated at the screening centre, 217 (6) per cent) from the Phase I recruitinent inethords and 99 ( 28 per cent) from Phase 2 efforts. Of these, 32 per cent were aged between 40 and 49 years and 21 per cent were over 70); the mean age was 58 years (1able 1). The ellunie origins of partic ipants were: Australian (57 per cent). Greek (17 per cent), British (11 per cent), Italian ( 3 per cent) and other (12 per cent).

In Phase 1, both approaches were equally costeffective (rable 2). Although the dosorstep method was more costly per participant, it was far more eflective in recruiting residents $(76$ per cent compared with 47 per cent for the lelephone method $\left(\chi^{\prime \prime}=31.26, P<0.001\right)$. In Phase 2 , dorstep interviewers successfully recruited a further 38 (45 per ceni) of the 84 who had originally resisted recruitment by either methoxl in Phase 1 , or who could not be contacted by telephone (lable 3 ). Senior field staff recruited a further 51 (52 per cent) out of 98 who had been approached earlier, and financial incentives succeeded in converting a further $10(9$ per cent-six for \$10 and four for \$25).

Table 3: Marginal cost-effectiveness of follow-up recruitment methods used in Phase 2

\begin{tabular}{|c|c|c|c|c|c|}
\hline $\begin{array}{l}\text { Recruitment } \\
\text { type }\end{array}$ & $\begin{array}{l}\text { Number } \\
\text { ottempted }\end{array}$ & $\underset{S}{C o s t}$ & $\begin{array}{c}\text { Effecti } \\
n\end{array}$ & $\begin{array}{c}\text { ness } \\
\%\end{array}$ & $\begin{array}{c}\text { Cost. } \\
\text { effectivoness } \\
S\end{array}$ \\
\hline $\begin{array}{l}\text { 2nd doorstep } \\
\text { Senior field staff } \\
\$ 10 \text { incentive } \\
\$ 25 \text { incentive }\end{array}$ & $\begin{array}{l}84 \\
98 \\
63 \\
42\end{array}$ & $\begin{array}{l}44 \\
38 \\
40 \\
59\end{array}$ & $\begin{array}{r}38 \\
51 \\
6 \\
4\end{array}$ & $\begin{array}{r}45 \\
52 \\
9 \\
9\end{array}$ & $\begin{array}{r}98 \\
73 \\
444 \\
655\end{array}$ \\
\hline
\end{tabular}

Nows:

(a) Indudes houschold roturols whiors it wos known thot of leost ons person wor digible to porticipote in the mominotion.

(b) Rosidents of housholds $(n-15)$ who contocted the sereening centro and concolled the $\$ 10$ incentive oppointment wore not cent a $\$ 25$ incentiva. 
residents did not participate will also be impxortant in ascertaining the barriers (1) screening attendance.

Based on these pilot results, we have chosen a iworstage approach: the docorstep method in Phase I, and follow-up strategies in Phase 2. for the Melbourne Visual Inpairment Projert. The evaluation has demonstrated the relative effertiveness of a iwo-phase approach to recruitment (an initial contact using a dourstep or personalised approach, and follow-up strategies) that should be relevant (t) many health rescarch settings.

\section{Acknowledgments}

The MVIP' is supported by the Victorian Health Promotion foundation and the NHMRC Sir John Ficles award (o) Professor H.R. Taylor.

\section{Reference}

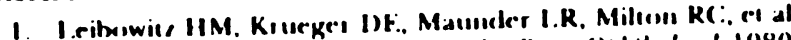
Framingham eye study momogiaph. Suri (phshalmol 1980): 24(suppl): $94.9-47$

2. (ianley JP. Roberts J. tiye comditions and related meed for medical care among persons 1-7i years of age. (/nited Slates. 1971-1972 care among persons 1 ital and health statistics. Series II, no. 228. Washington, IX): lital and health statistics. Series 1 (198.

- Taylor HR llleraviolet radiation and the eye: an epideniolengic study. Trans Am Ophehalmal Sior 1989: 87: 8U2-5.3.

4. Futderer F, Krueger DE, Mowery RI. Connell J. el al l.esuens from the visual acuity impairnent survey pilot study.

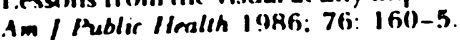

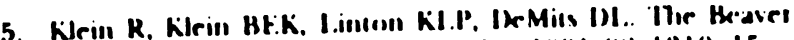

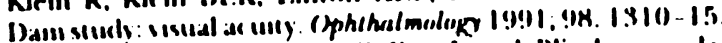

i. Tiels h jM. Semmer A. Will K. Kal/ J. re al. Hlinduess and vis.

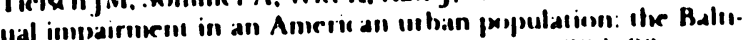

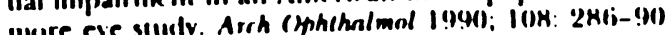

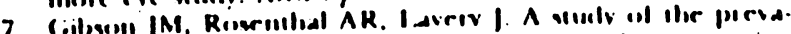

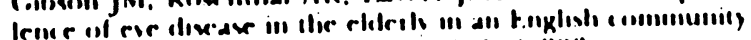

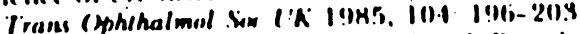

8. Marninre (iS. (aniplorll Al. Reinken I Prevalence ol ex ular

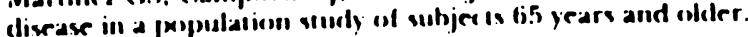
Am J Cphehalmal I!IHZ; !4: IKI-!

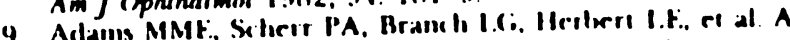

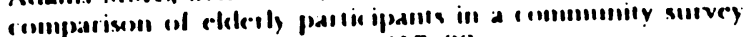
Public Health Kep 1!!(0): I1)!: (i) 7-22.

10. Australiall Hutcall of Sidistics $144 /$ consus o/ propulasion and

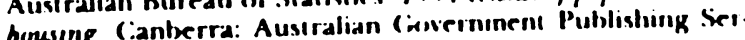
ic e. I!!)!.

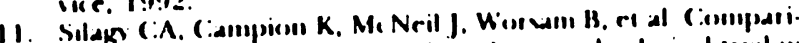

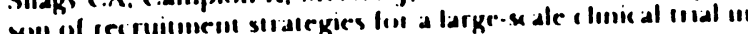
the elclerly. J (ilin tipidemiod I!!9!: 44: $11113-14$.

12. Hurler Sf. Folley D). I ivingsion IPM. Reading D, et al. Filter -

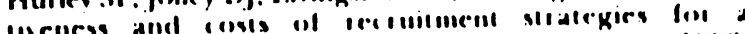

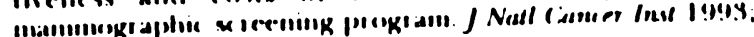
H4: 11 : H.5.5-6.3.

13. Tunibull D. Inwig I.. Ineflective recruilunent stralegies lor

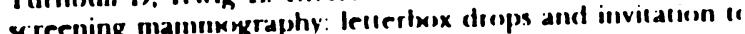
Iriends. Auss / Publer Mealth 19!92: 16: 79-81

14. Adelum P. Irwig I., Turnbull 1). tivaluating the inparl of a

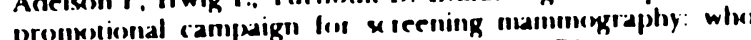
pronds? Aust J Mublir Imalth I?!?!: Ifi: fiti-7I

15. Michlill H. Hirst S. (inkhum ). Rracling I)/. el al. (Eervic al

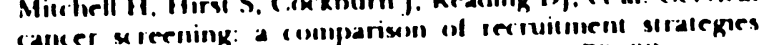
Cancer meter wouren. Med / Aust 1991: 155: 79-82

6. Ielecom natimal direstones. Meliwiume: Teler omill. 1999. 


\section{University Library}

\section{- M I N E R VA A gateway to Melbourne's research publications}

Minerva Access is the Institutional Repository of The University of Melbourne

Author/s:

Livingston, Patricia M.;Guest, Charles S.;Bateman, Angela;Woodcock, Norman;Taylor, Hugh R.

Title:

Cost effectiveness of recruitment methods in a population-based epidemiological study: the Melbourne Visual Impairment Project

Date:

1994

Citation:

Livingston, P. M., Guest, C. S., Bateman, A., Woodcock, N., \& Taylor, H. R. (1994). Cost effectiveness of recruitment methods in a population-based epidemiological study: the Melbourne Visual Impairment Project. Australian Journal of Public Health, 18(3), 314-318.

Publication Status:

Published

Persistent Link:

http://hdl.handle.net/11343/34444 